\title{
Five years after the accident, whiplash casualties still have poorer quality of life in the physical domain than other mildly injured casualties: analysis of the ESPARR cohort
}

\author{
Charlène Tournier ${ }^{\dagger}$, Martine Hours ${ }^{*}{ }^{\dagger}$, Pierrette Charnay, Laetitia Chossegros and Hélène Tardy
}

\begin{abstract}
Background: This study aims to compare health status and quality of life five years after a road accident between casualties with whiplash versus other mild injuries, to compare evolution of quality of life at 1 and 5 years after the accident, and to explore the relation between initial injury (whiplash vs. other) and quality of life.

Methods: The study used data from the ESPARR cohort (a representative cohort of road accident casualties) and included 167 casualties with "pure" whiplash and a population of 185 casualties with other mild injuries (MAIS-1). All subjects with lesions classified as cervical contusion (AIS code 310402) or neck sprain (AIS code 640278) were considered as whiplash casualties. Diagnosis was made by physicians, at the outset of hospital care, based on interview, clinical findings and X-ray. Whiplash injuries were then classified following the Quebec classification (grades 1 and 2). Quality of life was assessed on the WHOQoL-Bref questionnaire. Correlations between explanatory variables and quality of life were explored by Poisson regression and variance analysis.

Results: Between 1 and 5 years, global QoL improved for both whiplash and non-whiplash casualties; but, considering the two whiplash groups separately, improvement in grade 2 was much less than in grade 1 . At 5 years, grade-2 whiplash casualties were more dissatisfied with their health $(39.4 \% ; p<0.05)$ than non-whiplash $(24.3 \%)$ or grade-1 whiplash casualties (27.0\%). Deteriorated quality of life in the mental, social and environmental domains was mainly related to psychological and socioeconomic factors for both whiplash and other mildly injured road-accident casualties. While PTSD was a major factor for the physical domain, whiplash remained a predictive factor after adjustment on PTSD; unsatisfactory health at 5 years, with deteriorated quality of life in the physical domain, was observed specifically in the whiplash group, pain playing a predominant intermediate role.

Conclusions: Deteriorated quality of life in the physical domain remained 5 years after the accident, specifically in the grade- 2 whiplash group, pain playing a predominant intermediate role, which may be in line with the hypothesis of neuropathic pain.
\end{abstract}

Keywords: Whiplash, Quality of life, Comparison, ESPARR Cohort, Prospective study, 5 year follow-up, Mild injury, Road-accident injury

\footnotetext{
* Correspondence: martine.hours@ifsttar.fr

${ }^{\dagger}$ Equal contributors

Unité Mixte de Recherche Epidémiologique et de Surveillance Transport

Travail Environnement (UMRESTTE UMR_T 9405), Université Lyon 1,

Université de Lyon, Lyon, France
} 


\section{Background}

Defined as an acceleration-deceleration mechanism in the neck, whiplash is the most common injury in road accidents, particularly for motorists: over the 2007-2010 period (French road safety database), $35 \%$ of injured car occupants were concerned [1]. The annual incidence rate of casualties suffering from whiplash seems to be of the same order of magnitude in most countries (annual incidence between 0.04 and 3.2/1,000 inhabitants [2, 3]). A study of drivers in collisions involving two cars found similar results in French (1997-2003) and Spanish databases (2002-2004) [4]: $12.2 \%$ were diagnosed with whiplash in France and $12.0 \%$ in Spain.

Although considered a minor injury, whiplash is reported to generate both short- and long-term consequences, such as neck pain, headache, dizziness, sensory disorder and reduced neck mobility. These symptoms are often grouped together as "whiplash-associated disorder" (WAD) [5]. Whiplash injury and WAD have been widely described in the international literature: in most studies, more than half of whiplash casualties reported non-recovery 1 year after the accident [6-11]. Many studies also examined the relation between quality of life (QoL) and whiplash [8, 12, 13], some showing a correlation between post-traumatic stress disorder and lower QoL [14]. Psychological factors, such as psychological history ...., are often related to $\operatorname{WAD}[15,16]$. However, it is not clear if psychological factors are necessary and sufficient for non-recovery or if other sociodemographic or genetic factors may also play some role.

However, only a few studies [17, 18] compared chronicity in whiplash casualties versus other types of injury of similar severity. Chronic symptomatology may not be specific to whiplash, but dependent on personal (e.g., psychological) factors, as reported by the authors. If, however, whiplash casualties (unlike those with other comparable injuries) suffer specifically from chronical symptoms, and notably pain, it is necessary to further explore the possibility of neural lesions in the cervical region which may be the cause of neuropathic pain, as studied by Sterling and Pedler [19]. Furthermore, longterm (>1-year) follow-up of whiplash casualties is little documented in the literature [20-22].

A previous analysis of the mildly injured subjects of the ESPARR road-accident casualties cohort (ESPARR: Étude et Suivi d'une Population d'Accidentés de la Route dans le Rhône) showed that, 1 year after a low-severity road accident, subjects suffering from whiplash had recovered poorly compared to subjects with other minor injuries, that but QoL did not differ between whiplash and non-whiplash casualties [23]. The present study aimed to study the consequences of whiplash injury in the ESPARR cohort 5 years after the accident, in terms of pain, sequelae and QoL, and to compare them with those observed in the other mildly injured subjects. A secondary objective was to look for factors (notably whiplash status) associated with poorer quality of life in mildly injured subjects 5 years after the accident. Two underlying hypotheses were that psychological factors are significantly associated with persistent complaints, whatever the type of mild injury (not only whiplash) and that, in WAD, persistent pain accounts for complaints even in the absence of contributory psychological factors.

\section{Materials and methods \\ The ESPARR cohort}

The ESPARR project is a prospective cohort study of road accident casualties, which seeks to identify longterm consequences and to better define what constitutes serious injury. It is based on the Rhône Registry of Road Traffic Casualties [24], which, since 1995, has recorded all casualties receiving medical care in public or private health facilities in the Rhône administrative area of France. The inclusion criteria are: (1) having had a road traffic accident in the Rhône administrative area involving at least one mechanical means of transport; (2) living in the Rhône administrative area; (3) having survived the accident at least up to hospital admission; and (4) having received care in one of the area's hospitals. The injured are followed up for 5 years after the accident. All subjects have provided written consent.

Each individual lesion is coded using the Abbreviated Injury Scale (AIS) [25]: from 1 (minor injury) to 6 (fatal injury). The Maximum-AIS (M.AIS) is the injury's highest AIS score and defines overall initial injury severity.

The inclusion period for road accidents was initially from October $1^{\text {st }}, 2004$ to December $31^{\text {st }}$, 2005, later extended to July $31^{\text {st }}, 2006$ for the most seriously injured $(\mathrm{M} . \mathrm{AIS} \geq 3)$. The protocol has been described in detail in a previous publication [26].

The cohort comprises 1,168 adults, aged $\geq 16$ years at the time of the accident. At inclusion, the injured were asked to answer a questionnaire specifically drawn up for the ESPARR study, administered in a face-to-face interview.

The questionnaire gathered data on the accident and previous familial, occupational and health status. In addition, initial lesion assessment and other medical data (radiology, intensive care, etc.) were collected from medical records. Lesions were coded by the trained physician of the Registry from which the cohort was derived.

\section{Study population}

The present study selected the 546 adults in the ESPARR cohort who had sustained only mild injury, defined as maximum AIS level 1 (MAIS-1), excluding cases with associated AIS $\geq 2$ lesions in other body regions; 
253 of these subjects had sustained whiplash injury and the other 293 had any other type of MAIS-1 lesion, such as ankle or shoulder sprain, superficial wounds or contusions, tendon tear, etc. In all, 352 subjects (64.5\%) responded to the 5-year follow-up questionnaire (between October 2009 and December 2010): 167 of the 253 whiplash cases (66.0\%), comprising 63 grade- 1 and 104 grade- 2 injuries, and 185 of the 293 other mild injury casualties (63.1\%). $16 \%$ of non-whiplash and $20 \%$ of whiplash casualties failed to respond to the 1-year questionnaire.

\section{Clinical definition of whiplash}

In the present study, all subjects with lesions classified as cervical contusion (AIS code 310402) or neck sprain (AIS code 640278) were considered as whiplash casualties. Diagnosis was made by physicians, at the outset of hospital care, based on interview, clinical findings and X-ray. In the AIS classification, Code 310402 is attributed to neck pain following a road accident with painful neck on palpation without other objective signs, and corresponds to grade 1 in the Quebec classification; Code 640278 is attributed to neck pain associated with cervical stiffness and radiologic loss of cervical lordosis, and corresponds to grade 2 in the Quebec classification [23]. Cervical spine lesions graded AIS-1 (code 640278) but with associated neurologic abnormality (Quebec grade 3$)(n=2)$ were excluded.

\section{Variables and measurements}

\section{Outcome measurements at 5 years}

QoL was evaluated on the World Health Organization Quality of Life (Brief) (WHOQoL-Bref) questionnaire [27]. This tool contains 26 questions. The first two assess perception of overall QoL and perception of overall health, respectively. The other questions are categorized in four domains: physical, psychological, social and environmental [28]. Responses to each question are graded on a five-point Likert scale for intensity, capacity, frequency or evaluation, as the case may be (from $1=$ poor QoL, to $5=$ good QoL). Each of the four scores (one per domain) ranges from 4 to 20 , modified in the present study to 0-100 for comparison with WHOQOL-100 scores used in other studies. A high score indicates good QoL.

For analysis, the two generic questions (overall QoL and general health status) of the WHOQoL-Bref were coded as dichotomous variables: good or very good versus neither good nor bad, bad, very bad or no reply for overall QoL; and satisfied or very satisfied versus neither satisfied nor dissatisfied, dissatisfied, very dissatisfied or no reply for perception of overall health.

\section{Variable of interest}

The variable of interest for analysis was whiplash status, in three categories: non-whiplash, grade-1 whiplash, and grade-2 whiplash.

\section{Exploratory variables}

At inclusion, the questionnaire collected sociodemographic and accident-related data, plus some medical information and psychological history. Specifically, sociodemographic data comprised age, gender, family situation, educational level and socio-occupational category. Accident-related information comprised type of road-user with position inside the vehicle and impact direction, antagonist, reason for travel at time of accident, subjective responsibility for accident (admitting being at fault in the accident or not), friend or family member also injured in the same accident, and intention to lodge a complaint ${ }^{1}$. Financial problems (job loss, financial difficulties, failure) in the year before the accident and psychological history (sleep disorder, consumption of antidepressants/anxiolytics, regular appointments with a psychologist) in the year before the accident were also considered in this analysis.

Post-traumatic stress disorder (PTSD) at 6 months and/or 1 year after the accident was also taken into account and was assessed using the Post-traumatic CheckList Scale (PCLS) [29]. The PCLS includes 17 items relating to the 3 dimensions of the disorder (re-experiencing, avoidance and hyper-arousal), and has been shown to have good specificity for the diagnosis of PTSD; validation studies of the PCLS [29-32] have shown good psychometric properties. The validation of the French version [31] showed that PCLS score $\geq 44$ indicates presence of PTSD and the existence of disturbances which will necessarily affect lifestyle.

The presence of pain and sequelae of accident-related injuries was collected in the 5-year questionnaire. A free text about pain location allowed data to be classified according to body region (head, neck, face, spine, thorax, abdomen, upper limbs, and lower limbs); a dichotomous variable was created for each region (pain vs. no pain).

\section{Statistical analysis}

The representativeness of the study population (whiplash and non-whiplash subjects) was assessed by comparing sociodemographic and accident data between respondents and non-respondents at 5 years' follow-up. Descriptive statistics were used to describe the distribution of variables. $\mathrm{Chi}^{2}$ test (significance level, $5 \%$ ) or Fisher's exact test (small samples) were used for categoric variables; Student's test (normal data distribution) or Kruskal-Wallis test (non-normal data distribution) were used for continuous variables. 
QoL data (the two generic questions and mean scores in the 4 domains) collected at 1 and 5 years after the accident were compared for subjects responding at the both follow-up steps. Thus, it was possible to detect a significant improvement or deterioration in QoL for each group, using McNemar's test (significance level, $5 \%)$ or Student's test for matched data.

The next step was to identify factors for impaired QoL, with whiplash status as the variable of interest. Two modified Poisson regression models were built for each of the first two variables of the QoL scale: i.e., poor overall QoL and unsatisfactory overall health. Variance analysis was used to study each of the four QoL domains. Analysis strategy was identical in all models. Age and gender, considered as adjustment variables, were included in the multivariate analysis regardless of their significance level. The variable of interest (non-whiplash, grade-1 whiplash, grade- 2 whiplash) and explanatory factors at time of accident or at 1-year follow-up significantly associated $(\geq 10 \%)$ with outcome on univariate analysis were included in the multivariate analysis, after checking for collinearity between explanatory variables. Stepwise selection with backward elimination was applied, with $p>0.05$ for exclusion (model 1). For each outcome, the final model was built from model 1 , to which the variable "pain at 5 years" was added (model 2).

QoL was also analyzed separately for casualties with and without PTSD, and interactions between whiplash and pain were investigated.

Statistical Analysis System software, version 9.3 for Windows (SAS Institute Inc., Cary, NC, USA) (proc genmod and proc glm) was used for all analyses.

\section{Ethics and consent}

The study protocol was submitted to and approved by the French Ministry of Research (CCTIRS: Advisory Committee on Information Processing in Material Research in the Field of Health) (CCTIRS Number 04.159). Data collection and analysis were approved by the national data protection authority (CNIL: CNIL Number 041417). Lastly, only patients (or their family) who gave written consent for follow-up were included in the cohort. At any time during the follow-up period, subjects were free to cease participation, and, in that case, to be totally withdrawn from the study files and analyses.

\section{Availability of data}

Data are available from the authors upon request (CNIL's requirement).

\section{Results}

Representativeness of the study population

Respondents in the reference population (MAIS1, non-whiplash group) were, on average, older than non- respondents ( $34.0 \pm 14.8$ years vs. $30.1 \pm 14.7$ years at time of accident; $p<0.03)$. Their educational level was more often higher than school-leaving certificate $(29.7 \%$ vs. $16.7 \% ; p<0.03)$. There was no significant difference in terms of gender, family situation, occupation at time of accident, type of road user, reason for travel or body region involved (head, face, neck, thorax, abdomen, spine, upper limbs, or lower limbs).

Mean age at time of accident was not significantly different between respondents and non-respondents in the whiplash group. However, respondents were more numerous in the 35-45 years age-group (25.7\% vs. $8.1 \%)$ and less numerous in the $16-25$ years agegroup $(27.5 \%$ vs. $43.0 \%)\left(\mathrm{chi}^{2}\right.$ test; $\left.p<0.01\right)$. They were also more often in work at the time of the accident $(71.9 \%$ vs. $58.1 \% ; p<0.03)$. There was no significant difference in terms of gender, family situation, educational level, type of road user, reason for travel or body region involved.

There was no significant difference between the two grades of whiplash (grades 1 and 2) for respondents and non-respondents on sociodemographic, accident-related or injury characteristics.

\section{Characteristics of the populations}

Comparison between whiplash and non-whiplash casualties revealed several significant differences (Table 1). In particular, females were more numerous in the whiplash group; whiplash casualties were more frequently four-wheel motor-vehicle drivers, with accidents involving another motor vehicle, and with rear impact; subjective responsibility was less frequently reported in the whiplash group, while financial difficulties in the year before the accident were more frequent. By contrast, there were no significant differences between the whiplash and non-whiplash casualties in terms of psychological history or intention to lodge a complaint.

The reference population $(n=185)$ included 337 distinct lesions distributed between the 8 body regions (head, face, neck, thorax, abdomen, spine, upper limbs, and lower limbs): i.e., 1.8 minor lesions per casualty. The lower and upper limbs were the most frequently affected regions (35.0 and $23.1 \%$, respectively). The most frequent lesions were: lower-limb skin contusion (hematoma) (AIS code $810402 ; n=32$ ), knee contusion (AIS code 850802; $n=31$ ), and shoulder contusion (AIS code 751010; $n=21$ ).

In the year following the accident, $16.8 \%$ of whiplash casualties presented PTSD (grade 1: $17.5 \%$; grade 2: $16.3 \%$; non-whiplash casualties: $12.4 \%$ ), with no significant difference between groups (Table 1). Grade 1 and 2 whiplash casualties were compared on all analyses; no significant differences were found. 
Table 1 Sociodemographic and accident-related characteristics at inclusion for whiplash victims and non-whiplash victims

\begin{tabular}{|c|c|c|c|c|c|}
\hline & Non-whiplash victims & Whiplash victims & Chi $^{2}$ test ${ }^{l}$ & Whiplash vic & yy grade \\
\hline & $N=185$ & $N=167$ & & Grade $1=63$ & Grade $2=104$ \\
\hline & n (\%) & n (\%) & $P$-value & n (\%) & n (\%) \\
\hline Gender & & & $<0.0001$ & & \\
\hline Female & $72(38.9)$ & $106(63.5)$ & & $40(63.5)$ & $66(63.5)$ \\
\hline Male & $113(61.1)$ & $61(36.5)$ & & $23(36.5)$ & $38(36.5)$ \\
\hline
\end{tabular}

Age at the accident

$\begin{array}{lll}16-24 \text { years } & 65(35.1) & 46(27.5) \\ 25-34 \text { years } & 49(26.5) & 47(28.1) \\ 35-44 \text { years } & 30(16.2) & 43(25.7) \\ 45-54 \text { years } & 19(10.3) & 14(8.4) \\ \geq 55 \text { years } & 22(11.9) & 17(10.2)\end{array}$

Family situation

Single
In couple
Separated, divorced, widowed

$89(48.1)$

$79(42.7)$

$17(9.2)$

Educational level

$$
\begin{aligned}
& \text { <school-leaving cert. } \\
& \text { school-leaving cert. }
\end{aligned}
$$

>school-leaving cert.

Socio-occupational category

Farming, trade
Exec., sup. intellectual
Intermediate
Office worker
Manual
Student, housewife, other,
No
Yes
for travel
Journey to work/school
Work purposes
Other

Type of road-user
4-wheel motor
Other

92 (49.7)

38 (20.5)

55 (29.7)

$13(7.0)$

$22(11.9)$

$21(11.4)$

$71(38.4)$

$20(10.8)$

38 (20.5)

$147(79.5)$

$38(20.5)$

66 (35.7)

$6(3.2)$

$113(61.1)$

$76(41.1)$

$109(58.9)$

Place in vehicle

Driver
Front passenger
Rear seat passenger
Unknown passenger/no reply

$\begin{array}{ll}128(69.2) & 134(80.2) \\ 17(9.2) & 18(10.8) \\ 8(4.3) & 7(4.2) \\ 32(17.3) & 8(4.8)\end{array}$

NS

$\begin{array}{ll}20(31.7) & 26(25.0) \\ 13(20.6) & 34(32.7) \\ 16(25.4) & 27(26.0) \\ 4(6.3) & 10(9.6) \\ 10(15.9) & 7(6.7)\end{array}$

$<0.05$

59 (35.3)

$24(38.1)$

35 (33.7)

86 (51.5)

$32(50.8)$

54 (51.9)

$22(13.2)$

$7(11.1)$

15 (14.4)

NS

76 (45.5)

36 (21.6)

$55(32.9)$

5 (3.0)

23 (13.8)

17 (10.2)

83 (49.7)

$11(6.6)$

$28(16.8)$

$116(69.5)$

51 (30.5)

65 (38.9)

6 (3.6)

$96(57.5)$

145 (86.8)

22 (13.2)

$\begin{array}{ll}30(47.6) & 46(44.2) \\ 16(25.4) & 20(19.2) \\ 17(27.0) & 38(36.5)\end{array}$

NS

$\begin{array}{ll}4(6.3) & 1(1.0) \\ 8(12.7) & 15(14.4) \\ 5(7.9) & 12(11.5) \\ 28(44.4) & 55(52.9) \\ 3(4.8) & 8(7.7) \\ 15(23.8) & 13(12.5)\end{array}$

$<0.05$

$\begin{array}{ll}45(71.4) & 71(68.3) \\ 18(28.6) & 33(31.7)\end{array}$

NS

$\begin{array}{ll}20(31.7) & 45(43.3) \\ 4(6.3) & 2(1.9) \\ 39(61.9) & 57(54.8)\end{array}$

$<0.0001$

$\begin{array}{ll}52(82.5) & 93(89.4) \\ 11(17.5) & 11(10.6)\end{array}$

$<0.01$

$\begin{array}{ll}53(84.1) & 81(77.9) \\ 6(9.5) & 12(11.5) \\ 2(3.2) & 5(4.8) \\ 2(3.2) & 6(5.8)\end{array}$


Table 1 Sociodemographic and accident-related characteristics at inclusion for whiplash victims and non-whiplash victims (Continued)

\begin{tabular}{|c|c|c|c|c|c|}
\hline Antagonist & & & $<0.01$ & & \\
\hline None & $49(26.5)$ & $20(12.0)$ & & $4(6.3)$ & $16(15.4)$ \\
\hline Other (pedestrian, fixed obstacle...) & $28(15.1)$ & $21(12.6)$ & & $10(15.9)$ & $11(10.6)$ \\
\hline Motor vehicle & $108(58.4)$ & $126(75.4)$ & & $49(77.8)$ & $77(74.0)$ \\
\hline Impact direction $^{5}$ & & & $<0.0001$ & & \\
\hline Frontal & $33(17.8)$ & $35(21.0)$ & & $12(19.0)$ & $23(22.1)$ \\
\hline Rear & $7(3.8)$ & $56(33.5)$ & & $17(27.0)$ & $39(37.5)$ \\
\hline Lateral Right & $18(9.7)$ & $19(11.4)$ & & $6(9.5)$ & $13(12.5)$ \\
\hline Lateral Left & $12(6.5)$ & $27(16.2)$ & & $15(23.8)$ & $12(11.5)$ \\
\hline Don't know/no reply & $115(62.2)$ & $30(18.0)$ & & $13(20.6)$ & $17(16.3)$ \\
\hline Friend or family member involved ${ }^{6}$ & & & $\mathrm{NS}^{3}$ & & \\
\hline No & $142(76.8)$ & $115(69.5)$ & & $45(71.4)$ & $70(67.3)$ \\
\hline Yes & $43(23.2)$ & $51(30.5)$ & & $17(27.0)$ & $34(32.7)$ \\
\hline Intention to lodge a complaint & & & NS & & \\
\hline No & $111(60.0)$ & $99(59.3)$ & & $34(54.0)$ & $65(62.5)$ \\
\hline Yes & $18(9.7)$ & $22(13.2)$ & & $10(15.9)$ & $12(11.5)$ \\
\hline Don't know/no reply & $5630.3)$ & $46(27.5)$ & & $19(30.2)$ & $27(26.0)$ \\
\hline Subjective responsibility in accident & & & $<0.0001$ & & \\
\hline No & $52(28.1)$ & $92(55.1)$ & & $39(61.9)$ & $53(51.0)$ \\
\hline Yes & $48(25.9)$ & $34(20.4)$ & & $12(19.0)$ & $22(21.2)$ \\
\hline Don't know/no reply & $85(45.9)$ & $41(24.6)$ & & $12(19.0)$ & $29(27.9)$ \\
\hline Psychological history $^{7}$ & & & NS & & \\
\hline No & $129(69.7)$ & $105(62.9)$ & & $37(58.7)$ & $68(65.4)$ \\
\hline Yes & $56(30.3)$ & $62(37.1)$ & & $26(41.3)$ & $36(34.6)$ \\
\hline PTSD in the 1st Year & & & 0.05 & & \\
\hline No & $162(87.6)$ & $139(83.2)$ & & $52(82.5)$ & $87(83.7)$ \\
\hline Yes & 23 (12.4) & 28 (16.8) & & 11 (17.5) & $17(16.3)$ \\
\hline
\end{tabular}

${ }^{1}$ The test compares the group of the whiplash victims (all together) with the non-whiplash group

${ }^{2} \mathrm{NS}$ : non-significant

${ }^{3}$ Fisher's exact test

${ }^{4}$ Combination of several variables: job loss, financial difficulties, failure over the 12 months before the accident

${ }^{5}$ The impact direction was known only for the 4-wheel motor users; other road users are classified "no apply"

${ }^{6}$ Some non-respondent subjects: total does not equal $100 \%$

${ }^{7}$ Combination of several variables: sleep disorder, consumption of antidepressants/anxiolytics, regular appointments with a psychologist over the 12 months

before the accident

\section{Consequences at 5 years}

\section{Pain and sequelae}

Five years after the accident, whiplash casualties (in particular, grade 2) were twice as likely to report pain as non-whiplash casualties (40.7\% vs. $22.2 \%$ ) (Table 2). Whiplash casualties suffered from neck pain (grade 1, 22.2; grade 2, 33.7) and spine pain (other than cervical spine) $(12.7 \%$ and $20.2 \%$, respectively). Non-whiplash casualties complained of spine pain (7.0) and lower-limb pain $(9.7 \%)$. Only one in five of those reporting pain at 5 years had suffered from PTSD during the first year after the accident, whichever the group (53/68 whiplash and 33/41 non-whiplash casualties).
One in four whiplash casualty suffered from headache related to the accident (grades 1 and 2, $26.9 \%$; $10 \%$ for non-whiplash casualties; $p<0.0001$ ). Psychological sequelae were frequent in all three groups (grade 1, $20.6 \%$; grade 2, $27.9 \%$; non-whiplash, $17.3 \%$; non-significant difference).

There was no difference in terms of the impact of the accident on occupation or social and familial relations between whiplash and non-whiplash casualties (data not shown).

\section{Quality of life - comparison between data at 1 and 5 years after the accident}

In the whole group of respondents to the 5-year followup, one in four casualties reported less than good QoL. 
Table 2 Description of pain and sequelae for whiplash and non-whiplash victims, at 5 year post-road-accident

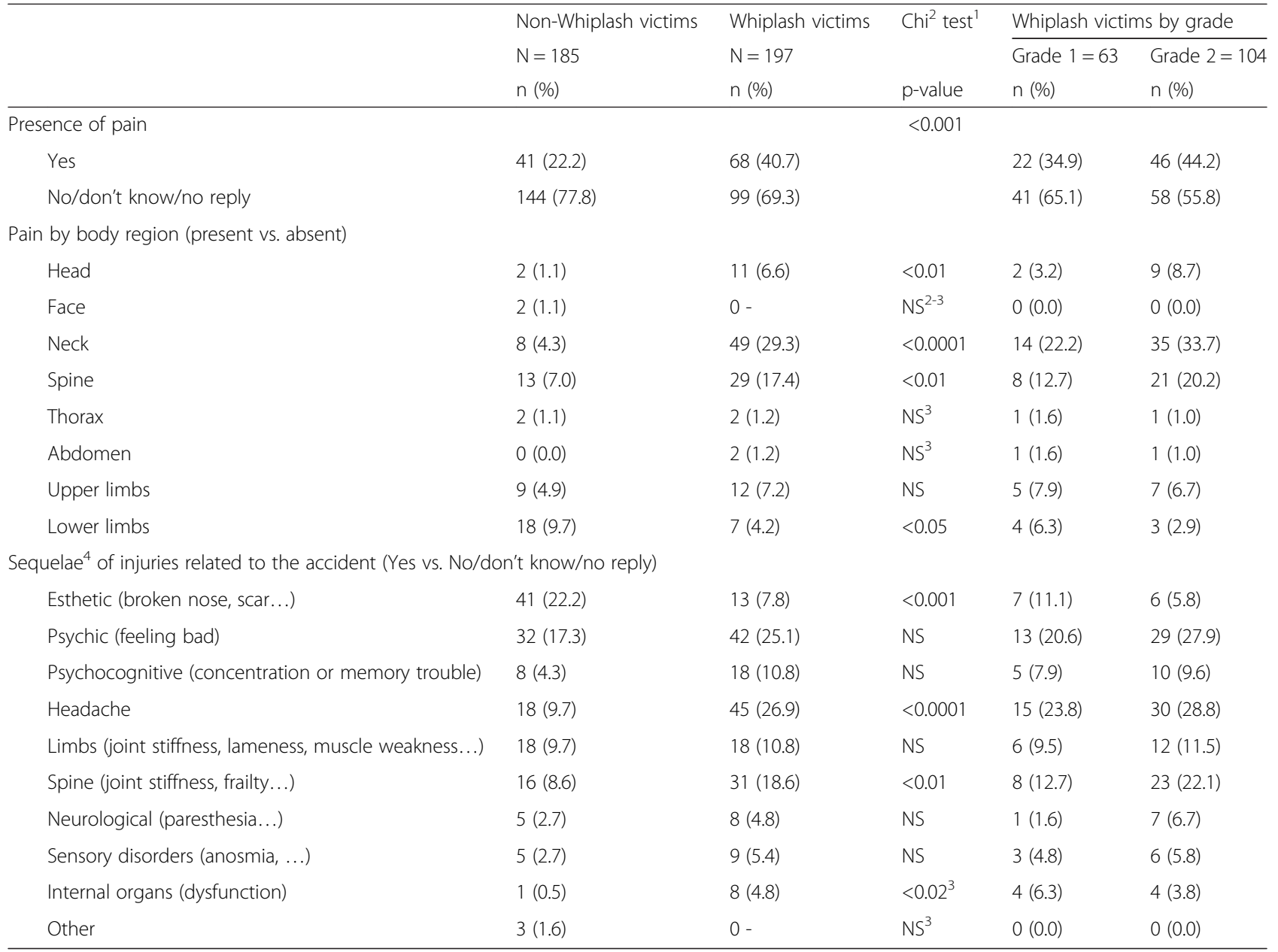

${ }^{1}$ The test compares the group of whiplash victims (all together) with the non-whiplash group

${ }^{2} \mathrm{NS}$ : non-significant

${ }^{3}$ Fisher's exact test

${ }^{4}$ other than pain

There was no significant difference between whiplash and non-whiplash casualties overall; however, grade-2 whiplash casualties were more dissatisfied with their health $(39.4 \%$; $p<0.05)$ than non-whiplash $(24.3 \%)$ or grade-1 whiplash casualties (27.0\%); whiplash casualties' mean scores were lower in the physical (grade 2, 75.2; grade $1,76.5$; vs. non-whiplash, $81.1 ; p<0.01)$ and psychological domains (respectively: 67.6, 67.1, and 71.2; $p<0.05)$.

Restricting analysis to respondents at both follow-up steps ( 1 and 5 years), results were fairly comparable for the non-whiplash and whiplash groups (Table 3). Global QoL improved for both whiplash and non-whiplash casualties; but, considering the two whiplash groups separately, improvement in grade 2 was much less. In terms of overall health at 5 years, improvement was less in the whiplash (grades 1 and 2) than the non-whiplash group; taking the two whiplash groups separately, however, grade1 casualties showed similar improvement to non-whiplash casualties, whereas grade- 2 casualties reported a status quo (non-significant decline) in health status (Table 3).

For non-whiplash casualties, scores in the physical, psychological and environmental domains were significantly higher $(p<0.001)$ at five years than one year (Table 3); for the grade-1 whiplash group, the improvement was significant for the psychological and environmental domains $(p=0.03)$, whereas there was no significant improvement for the grade-2 whiplash group. Scores in the psychological, social and environmental domains were quite similar at five years in the various groups, but the physical score remained lower in the whiplash group.

\section{Multivariate models: factors for impaired quality of life at 5 years after accident}

Perception of overall quality of life and of overall health

After adjustment on age and gender, whiplash status (Table 4) did not appear as a predictive factor for poorer 
Table 3 Comparison of the evolution of quality of life between 1 and 5 year after the accident

\begin{tabular}{|c|c|c|c|c|c|}
\hline & & $\begin{array}{l}\text { Non-whiplash } \\
(N=155)\end{array}$ & $\begin{array}{l}\text { Whiplash grade } 1 \text { et } 2 \\
(N=133)\end{array}$ & $\begin{array}{l}\text { Whiplash grade } 1 \\
(N=50)\end{array}$ & $\begin{array}{l}\text { Whiplash grade } 2 \\
(N=83)\end{array}$ \\
\hline & & n (\%) & n (\%) & n (\%) & n (\%) \\
\hline \multicolumn{6}{|l|}{ Global Items } \\
\hline \multirow[t]{2}{*}{ Good quality of life ${ }^{1}$} & 1 year & $108(69.7)$ & $95(71.4)$ & $34(68.0)$ & $61(73.5)$ \\
\hline & 5 years & $127(81.9)$ & $104(78.2)$ & $41(82.0)$ & $63(75.9)$ \\
\hline Improvement (\%) $)^{2}$ & & $+12.2^{b}$ & +4.8 & +14.0 & +2.4 \\
\hline \multirow[t]{2}{*}{ Satisfactory health status ${ }^{3}$} & 1 year & $108(69.7)$ & $88(66.2)$ & $34(68.0)$ & $54(65.1)$ \\
\hline & 5 years & $117(75.5)$ & $90(67.7)$ & $38(76.0)$ & $52(62.7)$ \\
\hline Improvement $(\%)^{2}$ & & +5.8 & +1.5 & +8.0 & -2.4 \\
\hline \multicolumn{6}{|l|}{ Domains } \\
\hline & & $\mathrm{m} \mathrm{SD}^{4}$ & $\mathrm{~m} \mathrm{SD}^{4}$ & $\mathrm{~m} \mathrm{SD}^{4}$ & $\mathrm{~m} \mathrm{SD}^{4}$ \\
\hline \multirow[t]{2}{*}{ Physical } & 1 year & $77.1(15.5)$ & $72.8(19.1)$ & $73.4(20.9)$ & $72.4(18.0)$ \\
\hline & 5 years & $81.5^{c}(13.9)$ & $76.2(17.9)$ & $76.0(17.6)$ & $76.2(18.2)$ \\
\hline Improvement $^{5}$ & & $+4.4^{c}$ & +3.4 & +2.6 & +3.8 \\
\hline \multirow[t]{2}{*}{ Psychological } & 1 year & $66.6(15.7)$ & $64.6(16.3)$ & $61.6(15.8)$ & $66.5(16.4)$ \\
\hline & 5 years & $71.1(13.6)$ & $69.0(15.3)$ & $67.2(17.0)$ & $70.1(14.2)$ \\
\hline Improvement ${ }^{5}$ & & $+4.5^{c}$ & $+4.6^{\mathrm{b}}$ & +5.6 & $+3.7^{\mathrm{a}}$ \\
\hline \multirow[t]{2}{*}{ Social } & 1 year & $73.2(19.5)$ & $71.6(19.9)$ & $68.9(20.9)$ & $73.3(19.3)$ \\
\hline & 5 years & $75.5(17.1)$ & $74.7(15.0)$ & $73.3(17.4)$ & $75.5(13.4)$ \\
\hline Improvement $^{5}$ & & +2.3 & +3.3 & +3.4 & +2.3 \\
\hline \multirow[t]{2}{*}{ Environmental } & 1 year & $68.0(16.5)$ & $65.0(16.3)$ & $65.3(17.7)$ & $64.8(15.5)$ \\
\hline & 5 years & $71.1(15.4)$ & 69.9 (16.6) & 71.7 (15.9) & $68.8(17.0)$ \\
\hline Improvement $^{5}$ & & $+3.1^{\mathrm{b}}$ & $+4.9^{c}$ & $+6.4^{\mathrm{a}}$ & $+4.0^{\mathrm{a}}$ \\
\hline
\end{tabular}

(non-whiplash, whiplash grade 1; whiplash grade 2) (restricted to subjects who responded at both one and 5 years; $N=288$ )

${ }^{a}<0.05 ;{ }^{\text {b }}<0.01 ;{ }^{c}<0.001$

${ }^{1}$ Grouping: good/very good vs. neither good nor bad/ bad/very bad/no reply

${ }^{2}$ McNemar's test

${ }^{3}$ Grouping: satisfied/very satisfied neither satisfied nor dissatisfied/dissatisfied/ very dissatisfied/ no reply

${ }^{4} \mathrm{SD}$ : standard deviation

${ }^{5}$ Student's test for matched data

overall QoL, but was related to unsatisfactory overall health, especially for grade- 2 whiplash $[R R=1.48$; $95 \% \mathrm{CI}=1.05-2.08]$ ); other factors (educational level, psychological history, intention to lodge a complaint and PTSD) seemed also to be associated with poorer overall QoL and unsatisfactory overall health. Interestingly, the results for the two whiplash groups were inversed at the 1-year follow-up: RR was higher in grade 1 than grade 2 .

When pain at five years was entered in the two previous models, it emerged as an intermediate factor for whiplash status (RR for whiplash status shifted from 1.43 to 1.24 (i.e., $>10 \%$ for overall QoL) and from 1.48 to 1.19 (i.e., $20 \%$ for overall health)). Pain was significantly associated with poorer overall $\mathrm{QoL}(\mathrm{RR}=1.96$; $95 \% \mathrm{CI}=[1.27-3.03])$ and unsatisfactory health $(\mathrm{RR}=$ $2.75 ; 95 \% \mathrm{CI}=[1.98-3.83])$. Intention to lodge a complaint and educational level ceased to be significant for "health status" outcome in the final model.
There was no interaction between pain and PTSD in the relation between whiplash and unsatisfactory health, in spite of higher relative risk for pain in the whiplash than in the non-whiplash group (Table 5).

\section{Scores on the 4 domains of quality of life}

Once adjusted for age and gender, presence of whiplash showed no relation to QoL in 3 domains (mental: $\beta=-1.82$ for grade 1 and $\beta=-2.14$ for grade 2; social: respectively $\beta=-1.00$ and $\beta=-1.12$; or environmental: respectively $\beta=+1.99$ and $\beta=-2.06)]$, and a borderline relation in the physical domain $(\beta=-1.46$ for grade 1 and $\beta=-3.71$ for grade $2 ; p=0.06)$. Psychological history and PTSD were predictive factors for impaired QoL in all 4 domains. Intention to lodge a complaint immediately after the accident was predictive in the physical domain, while educational level was not related to the social domain score. 
Table 4 Factors related to "not good quality of life" and "unsatisfactory health" at 5 years

\begin{tabular}{|c|c|c|c|c|c|c|c|c|}
\hline & \multicolumn{4}{|c|}{ Not good overall quality of life } & \multicolumn{4}{|c|}{ Unsatisfactory health } \\
\hline & Adj RR & $95 \% \mathrm{Cl}$ & Adj RR & $95 \% \mathrm{Cl}$ & Adj RR & $95 \% \mathrm{Cl}$ & Adj RR & $95 \% \mathrm{Cl}$ \\
\hline & \multicolumn{2}{|l|}{ Model 1} & \multicolumn{2}{|l|}{ Model 2} & \multicolumn{3}{|l|}{ Model 1} & Model 2 \\
\hline \multicolumn{9}{|l|}{ Adjustment factors } \\
\hline Age $>=35$ years & 2.10 & $1.41-3.13$ & 1.95 & $1.30-2.92$ & 1.23 & $0.89-1.69$ & 1.17 & $0.87-1.57$ \\
\hline Gender: female & 1.29 & $0.85-1.94$ & 1.13 & $0.74-1.72$ & 1.27 & $0.91-1.76$ & 1.00 & $0.73-1.37$ \\
\hline \multicolumn{9}{|l|}{ Other factors } \\
\hline \multicolumn{9}{|l|}{ Education level } \\
\hline$<$ school-leaving cert & 1.43 & $0.82-2.47$ & 1.10 & $0.61-1.99$ & 1.69 & $1.05-2.70$ & - & \\
\hline >school-leaving cert. & 0.62 & $0.31-1.24$ & 0.56 & $0.28-1.11$ & 1.12 & $0.65-1.93$ & - & \\
\hline Intention to lodge a complaint & - & & - & & 1.64 & $1.11-2.42$ & - & \\
\hline Psychological history & 1.63 & $1.11-2.38$ & 1.69 & $1.16-2.46$ & 1.61 & $1.18-2.20$ & 1.76 & $1.30-2.37$ \\
\hline PTSD & 1.97 & $1.30-2.98$ & 1.78 & $1.17-2.70$ & 1.61 & $1.16-2.24$ & 1.48 & $1.10-1.99$ \\
\hline \multicolumn{9}{|l|}{ Factor of interest } \\
\hline Whiplash grade 1 & 0.87 & $0.51-1.51$ & 0.80 & $0.47-1.36$ & 0.91 & $0.57-1.46$ & 0.83 & $0.53-1.30$ \\
\hline Whiplash grade2 & 1.43 & $0.93-2.17$ & 1.24 & $0.81-1.90$ & 1.48 & $1.05-2.08$ & 1.19 & $0.85-1.65$ \\
\hline Suffering from Pain at 5 years & - & - & 1.96 & $1.27-3.03$ & - & - & 2.75 & $1.98-3.83$ \\
\hline
\end{tabular}

(modified Poisson regression models), model 1 without pain in the model; model 2 with pain)

Integrating pain into the four previous predictive models, whiplash status was non-significant in all four domains. Pain was a major factor for diminished QoL score, mainly in the physical and environmental domains: the regression coefficient $(\beta)$ characterizing presence of pain five years after the accident was -13.55 (standard error $(\mathrm{SE})=1.79)$ for the physical domain, $-4.35(\mathrm{SE}=$ 1.70) for the psychological domain, $-5.85(\mathrm{SE}=1.92)$ for the social domain and $-8.55(\mathrm{SE}=1.79)$ for the environmental domain. Pain was a major intermediate factor between whiplash and QoL.

\section{Discussion}

\section{Interpretation of results}

Few studies have been published on the long-term quality of life of mildly injured road-accident casualties. The present study focused on minor injury (M.AIS $=1$ ) and tried to establish whether those suffering from whiplash (Quebec grades 1 and 2) differed in QoL five years after the accident. A further objective was to explore risk factors for impaired QoL. Results showed that, five years after mild road-crash injury, a significant number of patients still showed deteriorated quality of life, whatever the initial lesion. Furthermore, grade-2 whiplash subjects were more often dissatisfied with their health in terms of persistence of pain, and this was not explained by psychological history or development of PTSD.

Pain, headache and psychological sequelae related to the accident were strongly present in whiplash casualties five years after the accident, who were twice as likely to report pain as non-whiplash casualties (whiplash, $40.7 \%$; non-whiplash, $22.2 \%$ ), whereas pain was not more frequent in the whiplash group at 1 year [23]. This high percentage of residual pain is in agreement with literature reports. For example, Mayou et al. [17] showed that whiplash casualties were more often in pain than other casualty groups three years after the accident (whiplash injury, $30 \%$; other soft-tissue injury, $15 \%$; bone injury, $25 \%$; and no injury, $17 \%$ ), although these figures are much lower those reported by Stålnacke $(63 \%$ residual pain in

Table 5 Analysis of interactions between pain and PTSD related to unsatisfactory health

\begin{tabular}{|c|c|c|c|c|c|c|c|c|}
\hline & & \multicolumn{3}{|l|}{ Whiplash } & \multicolumn{3}{|l|}{ No whiplash } & \multirow{3}{*}{ Adjusted RR } \\
\hline & & \multirow{2}{*}{$\begin{array}{l}\text { Low health } \\
\text { status } \\
n\end{array}$} & \multirow{2}{*}{$\begin{array}{l}\text { Good health } \\
\text { status } \\
\mathrm{n}\end{array}$} & \multirow[t]{2}{*}{$\mathrm{RR}_{\text {(pain if Whiplash) }}$} & \multirow{2}{*}{$\begin{array}{l}\text { Low health } \\
\text { status } \\
\mathrm{n}\end{array}$} & \multirow{2}{*}{$\begin{array}{l}\text { Good health } \\
\text { status } \\
\mathrm{n}\end{array}$} & \multirow[t]{2}{*}{$R R_{\text {(pain if no Whiplash) }}$} & \\
\hline & & & & & & & & \\
\hline \multirow[t]{2}{*}{ No PTSD } & Pain & 28 & 25 & $3.03(1.79-5.12)$ & 13 & 20 & $2.31(1.31-4.08)$ & $2.67(1.82-3.93)$ \\
\hline & No pain & 15 & 71 & & 22 & 107 & & \\
\hline \multirow[t]{2}{*}{ PTSD } & Pain & 12 & 3 & $3.47(1.24-9.65)$ & 6 & 2 & $2.81(1.11-7.13)$ & $3.09(1.55-6.15)$ \\
\hline & No pain & 3 & 10 & & 4 & 11 & & \\
\hline
\end{tabular}


whiplash casualties five years after the accident) [33]. Whiplash casualties in the present study most often reported pain located in the neck $(29.3 \% ; 49$ out of 167$)$, compared to less than $5 \%$ of non-whiplash casualties; these figures are lower than in a Swedish study [21] (39.6\% of whiplash and $14.0 \%$ of non-whiplash casualties suffering from neck pain seven years after rear-end collision).

While overall QoL was not related to whiplash status, satisfaction with overall health was negatively correlated with whiplash, which is consistent with the analysis by domain: the only domain which was affected by whiplash was the physical domain. This was true even when gender, age, educational level, baseline psychological problems and post-accident PTSD were controlled for. Rebbeck et al. [8] also found a large proportion of subjects with whiplash not satisfied with their health status: almost half had not recovered two years after injury. Likewise, a recent Lithuanian study showed that whiplash casualties had worse general health status than matched controls [34].

Furthermore, comparison between data at one and five years showed an improvement in QoL in all groups (with or without whiplash) but, in grade-2 whiplash, QoL remained poorer than in the non-whiplash group five years after the accident; indeed, the mean physical score for the grade-2 whiplash group decreased at five years. Schwerla et al. [14] showed a significant improvement in the physical and mental component summary (SF-36) between the beginning and end of osteopathic treatment in subjects suffering from whiplash injuries. Rebbeck et al. [8] also showed significant improvement over time (follow-up at three and six months and two years) for the physical score (SF-36).

Psychological factors are often put forward as explaining the chronification of whiplash injury [11, 35]. In agreement with Holm [36], we think that non-recovery after a mild accident may be multifactorial and that psychological factors can be a contributing cause of WAD: in the present study, previous psychological factors were related to QoL in whiplash casualties. Similarly, PTSD is often suggested to be a predictive factor for poor QoL in the first years following an accident [37]: for example, in the present study, $16.8 \%$ of the whiplash group were suffering from PTSD at the one-year follow-up (12.4\% for non-whiplash casualties; non-significant difference). Similar results were reported by Mayou ${ }^{17}$ at 3 years, whiplash casualties tending to show a higher rate of PTSD (17\%) than other groups (non-significant difference). In the present study, PTSD was a major predictor of lower scores for all three domains (mental, social, environmental), whereas whiplash status was not; but, while PTSD was a major factor for the physical domain, whiplash remained a predictive factor after adjustment on PTSD.
The role of compensation has often been raised [11, 15, 38-41]. Sterling et al., however, found no association between lodging a claim and the persistence of moderate/severe symptoms for twelve months in whiplash casualties [42]. Several points should be noted: the present results were adjusted for the intention to lodge a complaint, and there was no correlation between PTSD and intention to lodge a complaint. Furthermore, in France, the financial costs of care are covered by national health insurance for everybody, and only a small fraction of the mildly injured lodge a compensation claim against a private insurance company; furthermore, lodging a complaint with the court is not mandatory for a compensation claim to be lodged against an insurance company. Interestingly, in our models, in spite of adjustment on these various factors, the relation between whiplash and lower satisfaction with overall health remained statistically significant. The difference in rate of pain after whiplash between the present study and many others may be explained by the general frequency of compensation claims in the various countries; but other factors may also interfere, such as true neurophysiological disturbance.

In fact, in the causal chain between the accident and lower satisfaction with health-related quality of life, the main question is the exact role of pain in the relation between whiplash and impaired long-term QoL. It is suggested that pain is strongly correlated with severe PTSD [43], but in some traumas this relation is not so clear [44]. Like Egloff et al., comparing psychological conditions in patients with chronic pain disorder with and without non-dermatomal somatosensory deficit [45], we found no difference in baseline psychological condition between study groups. Analyzing overall health in whiplash and non-whiplash casualties found no interaction between PTSD and pain.

Considering that the only significant difference between the two whiplash groups concerned the circumstances of the accident, and notably that psychological conditions were similar, the lack of improvement in the grade- 2 group, in marked contrast to the grade- 1 group, which greatly improved, can only be explained by pain, possibly neuropathic, related to a more severe initial neck injury; this could explain the perception of poorer overall health in the grade- 2 group, whereas the other domains were not related to whiplash. This point needs to be further investigated in future analyses.

\section{Strengths and limitations of the study}

Few studies deal with the long-term consequences of mild injury. The present study was based on the ESPARR cohort, which prospectively follows up a population of 1,168 road-accident casualties for 5 years. The ESPARR cohort is not specific to whiplash injury, so it can be expected that there is no selection bias: all 
patients managed in a public or private-sector hospital in a well-defined geographical area are included, whatever the severity and type of road accident [26]. The present analysis focused on the mildly injured (MAIS-1) members of the cohort, which explains the relatively small number of whiplash casualties. On the one hand, as the cohort does not focus on whiplash, no specific whiplash scale analysis, such as the Neck Disability Index (NDI) [46] or Neck Pain and Disability Scale (NPDS) [47], was used; furthermore, the questions on pain were not specific to any particular body region (e.g., neck), and subjects were free to specify any body regions affected by pain, thus enabling comparison between the two groups of mild injury without specifically focusing on neck pain. We thereby avoided introducing an information bias, whereas numerous whiplash studies analyzed only cohorts of whiplash casualties claiming compensation [48] or under treatment for chronic pain [49]. The present pain assessment was based on subjective response; this precluded investigating the existence of a neuropathic component as proposed by Sterling and Pedler [19]. On the other hand, as discussed by Carlesso et al. [50], not using a specific neck-pain questionnaire may have hidden some disabilities specifically related to whiplash; finally, Skevington et al. [51] pointed out that the use of WHOQoL-Bref may lead to poor detection of subtle differences, notably in the social domain. WHOQOL was built up from a long process of work, discussion and validation between specialists from a number of countries; in particular, the mental facet was framed by the definitions given by the DSM-IV [52].

At five years, information was obtained through a selfadministered questionnaire for all patients, and very few items were not answered; it is unlikely that bias could have been introduced in the analyses between the various groups, but it is possible.

Another point to be discussed is the possibility of an information bias related to non-respondents: the rate of non-response was quite similar in the whiplash and non-whiplash groups, and it is unlikely that this could have introduced any bias in the analysis. It seems that subjects who responded only to the five-year follow-up had slightly lower health status than those who responded to both follow-ups; but analysis restricted to the latter did not change the pattern of results. The same percentage of subjects participated in both followups (one and five years) in the two groups of whiplash casualties (grade 1: $79.3 \%$ and grade 2: $79.8 \%$ ), so the difference observed between the two grades was unrelated to response bias.

\section{Conclusion}

Deteriorated quality of life in the mental, social and environmental domains was mainly related to psychological and socioeconomic factors for both whiplash casualties and other mildly injured road-accident casualties. However, unsatisfactory health at five years, with deteriorated quality of life in the physical domain, was observed specifically in the whiplash group, pain playing a predominant intermediate role, which was not found at the one-year follow-up. Grade-2 whiplash casualties were particularly affected. The hypothesis of neuropathic pain might usefully be further explored.

\section{Endnote}

${ }^{1}$ In France, medical costs are payed by the national health insurance scheme; financial compensation is obtained through the driver's compulsory insurance. Lodging a complaint is essentially a way to obtain adjudication about responsibility, rather than financial compensation.

\section{Abbreviations}

AIS: Abbreviated Injury Scale; 95\%Cl: 95 \% confidence interval; DSM-IV: Diagnostic and Statistical Manual of Mental Disorders, 4th Edition; ESPARR: Etude et Suivi d'une Population d'Accidentés de la Route dans le Rhône (Follow-up study of road-crash casualties in the Rhône administrative area); MAIS: Maximum abbreviated injury scale; PTSD: Post-traumatic stress disorder; QoL: Quality of life; RR: Relative risk; WAD: Whiplash-associated disorder.

\section{Competing interest \\ The individual authors have no competing interests, financial or non-financial, to declare. \\ The current paper and the data have neither been published nor are under review elsewhere.}

\section{Authors' contributions}

$\mathrm{MH}$ and PC made substantial contributions to conception and design, and data acquisition; CT, LC, HT and MH made substantial contributions to data analysis and interpretation; $\mathrm{CT}$ and $\mathrm{MH}$ performed the literature search and data analysis and wrote the initial manuscript; LC and HT were involved in revising the manuscript critically for important intellectual content. All authors gave final approval of the version to be published, and agree to be accountable for all aspects of the work in ensuring that questions related to the accuracy or integrity of any part of the work are appropriately investigated and resolved.

\section{Authors' information \\ $\mathrm{MH}$ is a senior researcher (MD and PhD in epidemiology) \\ $\mathrm{PC}$ is an epidemiological researcher (MSc). \\ $C T, L C$ and HT are statisticians (MSC).}

\section{Acknowledgments}

The authors are grateful to the accident casualties for their cooperation in data collection.

The authors would like to thank all those who assisted in carrying out this study: Nadia Baguena, Jean-Yves Bar, Amélie Boulanger, Elodie Paquelet, Stuart Nash and Véronique Sotton for collecting the data; Irène Vergnes for organizing the databases; Anne-Marie Bigot, Nathalie Demangel and Geneviève Boissier for subject database management; Blandine Gadegbeku, Amina Ndiaye and The Association for the Rhône Road Trauma Registry (ARVAC) for their help in collecting and providing medical data; the Scientific Committee (Daniel Floret, Bernard Laumon, Jean-Michel Mazaux, Jean-Louis Martin and Etienne Javouhey); Dominique Boisson and Jacques Luauté for their participation in the ESPARR scientific management team; and all the hospital staff who accepted the interviewers' presence and referred casualties.

Special thanks to lain McGill for comments and manuscript editing. 


\section{Funding sources}

We acknowledge funding from the French Ministry of Equipment, Transport, Housing, Tourism and the Sea (Program Predit 3 "New Knowledge in the Field of Road Safety": № SU0400066), from the National Agency for Research (Program Predit "Safe, reliable and adapted transport" No. ANR-07-TSFA-007-01), from the French Ministry of Health (Program PHRC 2003: PHRC-N03 and PHRC 2005: PHRC- N051) and from the Road Safety Foundation (2010/MP/01/).

Received: 28 September 2015 Accepted: 18 December 2015 Published online: 05 January 2016

\section{References}

1. Observatoire national interministériel de la sécurité routière. La sécurité routière en France - bilan de l'année 2011. Paris: Observatoire national interministériel de la sécurité routière; 2012.

2. Hogg-Johnson S, van der Velde G, Carroll LJ, Holm LW, Cassidy JD, Gyuzman J, et al. The burden and determinants of neck pain in the general population. Results of the bone and joint decade 2000-2010 task force on neck pain and its associated disorders. J Manipulative Physiol Ther. 2008;32:S46-60.

3. Sterner Y, Toolanen G, Gerdle B, Hildingsson C. The incidence of whiplash trauma and the effects of different factors on recovery. J Spinal Disord Tech. 2003;16:195-9.

4. Martin JL, Perez K, Mari-Dell'olmo M, Chiron M. Whiplash risk estimation based on linked hospital-police road crash data from France and Spain. Inj Prev. 2008;14:185-90.

5. Sterling M. Clinical presentation of whiplash associated disorders. In: Sterling M, Kenardy J, editors. Whiplash: evidence base for clinical practice, vol. 1. Sydney: Churchill Livingstone: Elsevier Australia; 2011. p. 9-15.

6. Mayou R, Bryant B. Outcome of 'whiplash' neck injury. Injury. 1996;27:617-23.

7. Suissa S. Risk factors of poor prognosis after whiplash injury. Pain Res Manag. 2003;8:69-75.

8. Rebbeck T, Sindhusake D, Cameron ID, Rubin G, Feyer AM, Walsh J, et al. A prospective cohort study of health outcomes following whiplash associated disorders in an Australian population. Inj Prev. 2006;12:93-8.

9. Sterling M, Kenardy J. Introduction. In: Sterling M, Kenardy J, editors. Whiplash: evidence base for clinical practice. Elsevier Australia ed. Sydney: Churchill Livingstone: Elsevier Australia; 2011. p. xii-xv.

10. Ferrari R, Russel AS. Epidemiology of whiplash: an international dilemma. Ann Rheum Dis. 1999;58:1-5.

11. Carroll LJ, Holm LW, Hogg-Johnson S, Cote P, Cassidy JD, Haldeman S, et al. Course and prognostic factors for neck pain in whiplash-associated disorders (WAD): results of the Bone and Joint Decade 2000-2010 Task Force on Neck Pain and Its Associated Disorders. Spine. 2008;33:S83-92.

12. Baumann C, Erpelding M, Regat S, Collin J, Briancon S. The WHOQOL-BREF questionnaire: French adult population norms for the physical health, psychological health and social relationship dimensions. Rev Epidemiol Sante Publique. 2010;58:33-9.

13. Ferrari R, Russell AS, Connor-Spady B. The medical outcome study short form 6D and whiplash. J Rheumatol. 2005;32:1849-50.

14. Schwerla F, Kaiser AK, Gietz R, Kastner R. Osteopathic treatment of patients with long-term sequelae of whiplash injury: effect on neck pain disability and quality of life. J Altern Complement Med. 2013;19:543-9.

15. Scholten-Peeters GM, Verhagen P, Bekkering GE, Van der Windt DA, Barnsley L, Oostendorp RAB, et al. Prognostic factors of whiplash-associated discorders: a systematic review of prospective cohort studies. Pain. 2003;104:303-22

16. Buitenhuis J, de Jong PJ, Jaspers J, Kenardy J. Psychological aspects of whiplash associated disorders. In: Pike C, editor. Whiplash: evidence base for clinical practice, vol. 1. Australia: McEvoy, Melinda: Elsevier Australia ed. Chatswood; 2011. p. 85-92.

17. Mayou RA, Bryant B. Psychiatry of whiplash neck injury. Br J Psychiatry 2002;180:441-8.

18. Kasch H, Bach FW, Stengaard-Pedersen K, Jensen TS. Development in pain and neurologic complaints after whiplash: a 1-year prospective study. Neurology. 2003;60:743-9.

19. Sterling M, Pedler A. A neuropathic pain component is common in acute whiplash and associated with a more complex clinical presentation. Man Ther. 2009;14:173-9.
20. Squires B, Gargan MF, Bannister GC. Soft-tissue injuries of the cervical spine. 15-year follow-up. J Bone Joint Surg (Br). 1996;78:955-7.

21. Berglund A, Alfredsson L, Cassidy JD, Jensen I, Nygren A. The association between exposure to a rear-end collision and future neck or shoulder pain: a cohort study. J Clin Epidemiol. 2000;53:1089-94.

22. Bunketorp L, Nordholm L, Carlsson J. A descriptive analysis of disorders in patients 17 years following motor vehicle accidents. Eur Spine J. 2002;11:227-34

23. Hours M, Khati I, Charnay P, Chossegros L, Tardy H, Tournier C, et al. One year after mild injury: comparison of health status and quality of life between patients with whiplash versus other injuries. J Rheumatol. 2014; $41: 528-38$

24. Laumon B, Martin JL, Collet P, Chiron M, Verney MP, Ndiaye A, et al. A French road accident trauma registry : first results. In: 41st AAAM conference: 10-11 novembre 1997 1997. Orlando, Florida: Association for the Advancement of Automotive Medicine (AAAM); 1997. p. 127-37.

25. Association for the Advancement of Automotive Medicine. The Abbreviated Injury Scale-1990 Revision (AIS-90). In. Des Plaines, IL; 1990.

26. Hours $M$, Bernard $M$, Charnay $P$, Chossegros L, Javouhey $E$, Fort $E$, et al. Functional outcome after road-crash injury: description of the ESPARR victims cohort and 6-month follow-up results. Accid Anal Prev. 2010;42:412-21.

27. The WHOQOL Group. Development of the World Health Organization WHOQOL-BREF quality of life assessment. Psychol Med. 1998;28:551-8.

28. Skevington SM, Lotfy M, O'Connell KA, group TW. The World Health Organization's WHOQOL-BREF quality of life assessment: psychometric properties and results of the international field trial. A report from the WHOQOL group. Qual Life Res. 2004;13:299-310.

29. Weathers FW, Litz BT, Herman DS, Huska JA, Keane TM. The PTSD checklist: Reliability, validity and diagnostic utility. San Antonio: IXth Annual Meeting of the International Society for Traumatic Stress Studies; 1993.

30. Blanchard EB, Hickling EJ, Taylor AE, Loos WR, Gerardi RJ. Psychological morbidity associated with motor vehicle accidents. Behav Res Ther. 1994;32:283-90.

31. Ventureyra V, Yao S-N, Cottraux J, Note I, De Mey-Guillard C. The validation of the posttraumatic stress disorder checklist scale in posttraumatic stress disorder and nonclinical subjects. Psychother Psychosom. 2002;71:47-53.

32. Yao SN, Cottraux J, Note I, De Mey-Guillard C, Mollard E, Ventureyra V. Evaluation of post-traumatic stress disorder: validation of a measure, the PCLS. Encéphale. 2003:29:232-8.

33. Stålnacke B-M. Relationship between symptoms and psychological factors five years after whiplash injury. J Rehabil Med. 2009;41:353-9.

34. Pajediene E, Janusauskaite J, Samusyte G, Stasaitis K, Petrikonis K, BileviciuteLjungar I. Patterns of acute whiplash-associated disorder in the Lithuanian population after road traffic accidents. J Rehabil Med. 2014:47:52-7.

35. Versteegen GJ, Dijkstra PU, Jaspers JP, Meijler WJ, ten Duis HJ, Klip EC. Sprain of the neck: quality of life and psychological functioning. A 4-year retrospective study. Qual Life Res. 2003;12:335-43.

36. Holm L. Epidemiology of whiplash associated disorders. In: Sterling M, Kenardy J, editors. Whiplash: evidence base for clinical practice, vol. 1. Elsevier Australia: Elsevier Australia ed. Sydney: Churchill Livingstone; 2011. p. 1-8

37. Johansen VA, Wahl AK, Eilertsen DE, Weisaeth L, Hanestad BR. The predictive value of post-traumatic stress disorder symptoms for quality of life: a longitudinal study of physically injured victims of non-domestic violence. Health Qual Life Outcomes. 2007;5:26.

38. Elbers NA, Akkermans AJ, Cuijpers P, Bruinvels DJ. Procedural justice and quality of life in compensation processes. Injury. 2012;44:1431-6.

39. Côté P, Cassidy JD, Carroll L, Frank JW, Bombardier C. A systematic review of the prognosis of acute whiplash and a new conceptual framework to synthesize the literature. Spine. 2001;26:E445-458.

40. Versteegen GJ, Kingma J, Meijler WJ, ten Duis HJ. Neck sprain after motor vehicle accidents in drivers and passengers. Eur Spine J. 2000;9:547-52.

41. Freckelton I. Whiplash and the law. In: Kenardy MSJ, editor. Whiplash: evidence base for clinical practice, vol. 1. Elsevier Australia: Elsevier Australia ed. Sydney: Churchill Livingstone; 2011. p. 157-67.

42. Sterling M, Hendrikz J, Kenardy J. Compensation claim lodgement and health outcome developmental trajectories following whiplash injury: a prospective study. Pain. 2010;150:22-8.

43. Egloff N, Hirschi A, von Kanel R. Traumatization and chronic pain: a further model of interaction. J Pain Res. 2013;6:765-70. 
44. Nampiaparampil DE. Prevalence of chronic pain after traumatic brain injury. A Systematic Review JAMA. 2008;300:711-9.

45. Egloff N, Maecker F, Stauber S, Sabbioni ME, Tunklova L, von Känel R. Nondermatomal somatosensory deficits in chronic pain patients: are they really hysterical? Pain. 2012;153:1847-51.

46. Wlodyka-Demaille S, Poiraudeau S, Catanzariti JF, Rannou F, Fermanian J, Revel M. French translation and validation of 3 functional disability scales for neck pain. Arch Phys Med Rehabil. 2002;83:376-82.

47. Wheeler AH, Goolkasian P, Baird AC, Darden BV 2nd. Development of the neck pain and disability scale. Item analysis, face, and criterion-related validity. Spine (Phila Pa 1976). 1999:24:1290-4.

48. Côté P, Cassidy JD, Carroll L. Is a lifetime history of neck injury in a traffic collision associated with prevalent neck pain, headache and depressive symptomatology? Accid Anal Prev. 2000;32:151-9.

49. Williamson E, Williams MA, Gates S, Lamb SE. Risk factors for chronic disability in a cohort of patients with acute whiplash associated disorders seeking physiotherapy treatment for persisting symptoms. Physiotherapy. 2015;101:34-43

50. Carlesso LC, Walton DM, Macdermid JC. Reflecting on whiplash associated disorder through a QoL lens: an option to advance practice and research. Disabil Rehabil 2011. 2011;34:1131-9.

51. Skevington S, McCrate F. Expecting a good quality of life in health: assessing people with diverse diseases and conditions using the WHOQOL-BREF. Health Expect. 2012;15:49-62.

52. Aigner M, Forster-Streffleur S, Prause W, Freidl M, Weiss M, Bach M. What does the WHOQOL-Bref measure? Measurement overlap between quality of life and depressive symptomatology in chronic somatoform pain disorder. Soc Psychiatry Psychiatr Epidemiol. 2006;41:81-6.

\section{Submit your next manuscript to BioMed Central and we will help you at every step:}

- We accept pre-submission inquiries

- Our selector tool helps you to find the most relevant journal

- We provide round the clock customer support

- Convenient online submission

- Thorough peer review

- Inclusion in PubMed and all major indexing services

- Maximum visibility for your research

Submit your manuscript at www.biomedcentral.com/submit 